\title{
A Comprehensive Framework for Adaptive E-Learning Management System
}

\author{
Shinoj Robert, Maria Dominic
}

\begin{abstract}
The various e-Learning systems in recent times found to be ineffective in directing the individual learning style with the preferred learning abilities. Focusing on this inadequacy, this paper proposes a comprehensive study from the different styles on the existing frameworks engaging an adaptive learning algorithm that applies a data stream technique using Machine Learning for a better learning path. The adaptation process insists or allow the user to modify the parameters and to adapt the behaviour according to the system assumption. When the system adapts to a personal concept and responds, it is said to be a personalized process. This concentrate and generates more ideas and style towards student-centric learning and creating a new learning path for an individual or group of learners. This generic framework is grounded on four-dimension. This framework tailors the learning style according to the individual learning types by creating a specific learning objective by incorporating learning modules, personalization and learner Noesis with technologies
\end{abstract}

Keywords: e-Learning, learning abilities, Machine Learning, adaptive learning, data stream, user profile.

\section{INTRODUCTION}

Learning skills acquired by humans are mostly related to the psychological relating factors i.e. cognitive in style. The technology that we build makes the learning process easier and made available at any point in time. Learning is not a single way for sharing the resources and information, it has several channels for streamlining the resources. The effective way of sharing the information is done through e-learning and the tools utilized for sharing the resources.

\section{LEARNING}

\section{A. E-learning}

The term e-Learning comes into existence at the end of the $19^{\text {th }}$ century as CBT (Computer Based Training). It has a similar word to "virtual" and "online" [1]. In turn, e-learning implies and consumes electronic devices for active participation.

In the current education trend learning via mobile phone paves a greater enhancement for student, teacher and other learner categories.

Revised Manuscript Received on December 30, 2019.

* Correspondence Author

Shinoj Robert*, Research Scholar, Department of Computer Science, Sacred Heart College, Tirupattur, India. Email: shinojrobert@gmail.com

M. Maria Dominic, Assistant Professor, Department of Computer Science, Sacred Heart College, Tirupattur, India. Email: dominic@shctpt.edu

(C) The Authors. Published by Blue Eyes Intelligence Engineering and Sciences Publication (BEIESP). This is an open access article under the CC-BY-NC-ND license http://creativecommons.org/licenses/by-nc-nd/4.0/
The use of e-Learning is made possible and achieved through the extension of the internet. e-learning paves the way for reusing, sharing resources and interoperability. These services are provided by most organizations through e-learning tools. The recent trends e-learning tools are handled below. The other trade names given for e-Learning are figured below.

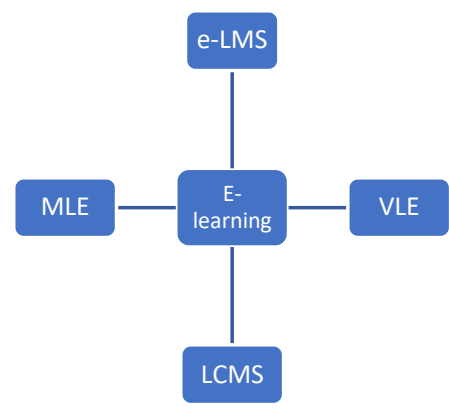

Fig. 1.Various Trade Name for e-learning

\section{E-LEARNING TOOLS}

E-learning also known as digital learning. Technology applied learning is totally a new version of learning instead of technology through learning. Technology applied learning insist that technology is one of the media of instruction among the other possible one that is being used for course delivery. Rather, technology through learning explicit that technology is the sole conduit of instructions through which the learner and instructor get communicated and benefitted [2]. In this e-learning tools fall on to the first category of learning, where technology supports through digital media like CMS, WWW, etc.

The course management delivery is made possible via online by the different learning tools. It helps in categorizing and conducting various activities to test learner behaviour. The learning tools consist of different activities that pave the way for introducing the dimensions of the teaching-learning process. The most familiar tool to fit under the discussion is MOODLE (Modular Object-Oriented Dynamic Learning Environment). Some of the familiar and most popular tools that are practiced by the digital learners collected from various online journals were presented as an evident factor for the above learning tools prescribed. 


\section{A Comprehensive Framework for Adaptive E-Learning Management System}

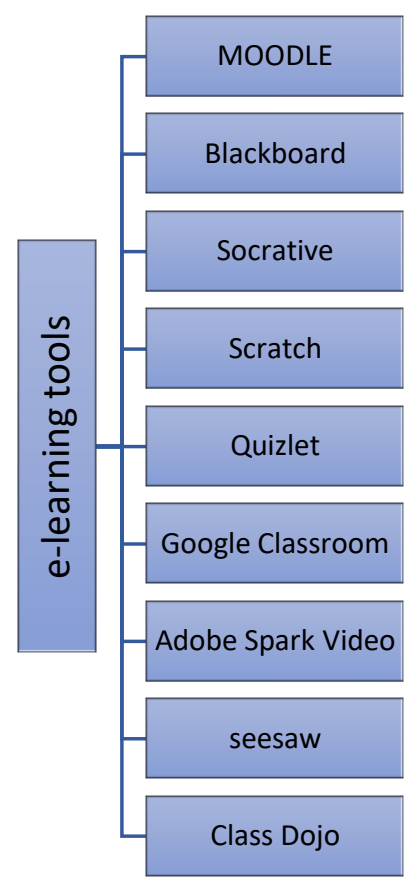

Fig. 2. Recent e-learning Management System.

\section{A. Moodle}

[3] MOODLE stands for Modular Object-Oriented Dynamic Learning Environment. The MOODLE is a common online course management tool that connects the instructor and the learner either in synchronous, asynchronous and blended ways of learning. In the modern era of education. The various activities in this tool helps the learners for the continuous learning process. Some of the well-known activities carried out are assignment, Quiz, Forum, Lesson, page, Files, Glossaries, etc. The current version of MOODLE had moved to the analytics platform where the system provides individual learning styles according to the learning behavior of the individual. The mobile application version helps the learners to stay connected even out of the classes through the activities.

\section{B. Blackboard}

[4] The Blackboard Learning Management System is an online tool that automates and manages the courses online. It is a popular web-based learning compared to MOODLE. Blended learning is made possible by conducting flipped classrooms. Learner receives a curation notification on the courses they have opted by mobile. One on one tutoring is carried out for effective teaching online in and out of the class. Course content is made instantly available to the learners. Blackboard collaborates with the unbounded learning method. The digital learning video and audio interactions by the tutor and the learner creates a seamless learning interaction. The application version makes the learner capabilities together into a single contained learner-centric solution.

\section{Socrative}

[5] Socrative enriches the teaching-learning environment by conducting activities like quizzes, worthful and timely feedback from the tutors through the web browser set up. It is a cloud-based response from the learner (student). The learner can have a fast response from the tutor. The activities in this web-based learning are quizzes, feedback, etc.

\section{Scratch}

[6] Scratch Focuses on a teenage group of learners making them engage programming oriented. Music and other entertainment activities can be blended with a scratch learning environment. An interactive learning environment is created between the learner and the tutor.

\section{E. Quizzlet}

[7] The quizlet web-based learning platform helps the leaners to share the files which include diagrams and flashcards. The targeted group is focused on this kind of learning. Activities are classified and arranged according to the learner-centric approach. For example, a study remainder is an activity that works with a combination of machine learning and spaced repetition. Learn, Flashcards, Write, Spell, Test, Match and audio learning are used for engaging different learning techniques.

\section{F. Google Classroom}

[8] This is one of the familiar and most used web-based services to the e-learning platforms. The activities engaged here are file sharing, create Assignment, communication via paperless way. It is a free online learning platform accessed through G-suite. It is the easiest way to connect with the student through a single channel approach i.e. the learner gets access to the mail provided to their account.

\section{G. Adobe Spark Video}

[9] The adobe spark video is a strange web-based learning tool for presenting the videos and slides. A series of presentations could be created for the institute or a company. Getting started with spark video, it is a free service for primary tools and paid service when the learner wants to improve the learning with a personalized approach like logo creation, colors, brand design with graphics, themes, and phone support. The content learner chooses will make them to get involved more in this type of learning. Some of the familiar contents are Portfolio, Advertisement, Animated Story, etc. The significant activities are teaching \& Inspiring, tell a story and Impress at work. Learner who prefers for a professional way of learning can adopt this kind of web-based learning.

\section{H. Seesaw}

[10] Seesaw is an online digital learner-driven portfolio where the learner can publish and create a job. The communication between the tutor, peer learner and the audience will take place. Unlike the MOODLE and Blackboard, the leaner can upload their activities which include video, audio recording, file attachment, and painting options. The tutor can later watch this and approve or delete the content that is subject to matter. The create and share activity helps the learners to learn as a peer group. It is one of the best online learning management system.

\section{ClassDojo}

[11] ClassDojo is a powerful online learning tool, to keep track of the learner's progress using behavior and to stay connected with parents by attendance. This online learning management encourages education through gamification. The learner can showcase their talents by adding videos, images, sounds, and notifications on digital platforms. The main feature in this learning platform is adding multiple learners at the same time and track their performances by an alert indicator listing their performance status. The tutor keeps running the total on the learner performances.

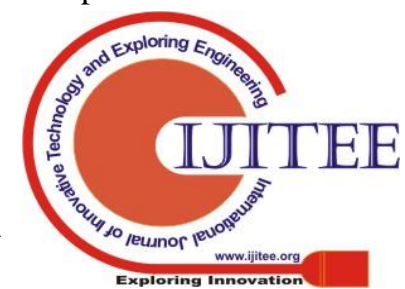


The overall classification of the learners will display the points, award notifications, positive and negative. The class performance can be monitored. Parent has a separate login account to keep track of their children as a learner.

\section{LEARNING TYPES}

Learning is a life long journey, which chip and bring effective changes in society. The journey towards learning leads to self-discovery through knowledge acquisition. But more important is to share experiences of what the learners learned. The learning ability and styles of students are unbounded in nature. Learning has got different names, in fact, a one who understood about it may have a variety of statements and meanings to it. Some of the statements are classified in the below table.

Table-I: Hoarded names for learning in recent times

\begin{tabular}{|l|l|}
\hline Type & \multicolumn{1}{|c|}{ Statement } \\
\hline \multirow{4}{*}{ Learning } & Brainiac changes made to the brain \\
\cline { 2 - 2 } & Chemical processing in the thinking \\
\cline { 2 - 2 } & Remembrance and Recall of the activity \\
\cline { 2 - 2 } & Knowledge Building \\
\cline { 2 - 2 } & Dynamic and existential \\
\hline
\end{tabular}

\section{LEARNING STYLES}

The learning style differs from person to person. The learner opts to litigate the information, unlike other learner categories. This automatically creates an interest in listening to the instructions and learning when they follow their own formats of learning [12]. Learning has its own structure. The structure includes input and actioning of information. In the footstep of input, the student (learner) will select the stuff based on the external and internal items. The internal factors focus on the senses while the external is about behaviors and habits. The followed actioning step includes the interaction with others. The interactions could be made in the form of self-contemplation or influencing factors. The outcome achieved here by the learner is through the stuff that made really useful in the improvement of the learning standard. Every learner has a favored way of input and actioning the information which leads to the articulation in learning styles. The scientist has proven, human brain converts the spoken words to the written format and the written words in an equivalent manner. It is impossible to produce everything that the learner visualizes. Instead, when the learner trains to adopt the learning style in visual and verbal, it could result in equal to the written style of communication. This kind of approach paves the way in creating a new learning style category.

Table-II: Sarasin Learning Model

\begin{tabular}{|c|c|}
\hline Learning Style & Description \\
\hline \multirow{3}{*}{ Sarasin Learning Model } & Auditory \\
\cline { 2 - 2 } & Visual \\
\cline { 2 - 2 } & Kinesthetics \\
\hline
\end{tabular}

The Learning Style of the learners is based on psychological inquiries. Table 1 figures the sarasian learning styles based on sensitive abilities related to the learner (student). Kolb's learning style is also used as a common approach in the research.
Table-III: Felder-Silverman-Based Learning Model

\begin{tabular}{|l|l|}
\hline \multicolumn{1}{|c|}{ Learning Style } & \multicolumn{1}{c|}{ Description } \\
\hline Visceral & Abstract Learning \\
\hline Broody & Deep Learning \& Thinking \\
\hline Optic & Visual Learning \\
\hline Prolix & Writing skill \\
\hline Consecutive & Learning by succession \\
\hline Outright & $\begin{array}{l}\text { Learning without limitless, } \\
\text { learning by skipping. }\end{array}$ \\
\hline
\end{tabular}

The learning style will help the teacher to have more interaction with a student which will enhance the teaching-learning process and will result in an increased perception of designing effective activities inside the classroom. The Machine Learning Techniques help the betterment of students to choose the learning styles [13].

\section{RECENT E-LEARNING MODELS}

In recent times, online learning has reached the advanced level through popular learning models. These learning models bridge the learning techniques and pour a reasonable solution by adopting various styles that carried out in recent learning

Table- IV. Recent E-learning Model

\begin{tabular}{|c|c|}
\hline Learning Model & Description \\
\hline AFT & Action Feedback \& Trigger \\
\hline SAM & Successive Approximation Model \\
\hline ASSURE & Integrating Technology into Instructor-Led \\
Training
\end{tabular}

\section{A. AFT Model}

[14] The AFT model finds the solution for certain limitations in an online learning platform where the learner learns by the video tutorials and not possessing any experimental learning. The online engagement for this experimental type of learning is brought through the AFT model. The model builds the Action which in turn transforms into feedback that triggers the learner disabilities areas and provides improvement measures. The feedback depicts the evidence for learning and it will boost the confidence level of the learner. In the case of no feedback, the learner demotivated about the performance and leads to depression.

Table-V: AFT Model Representation

\begin{tabular}{|c|c|}
\hline Symbol & Description \\
\hline $\mathrm{A}$ & Action \\
\hline $\mathrm{F}$ & Feedback \\
\hline $\mathrm{T}$ & Trigger \\
\hline
\end{tabular}

\section{B. SAM Model}

[15] SAM (Successive Approximation Model) is an instructional based model. It is the successor model and alternative to the ADDIE model approach. ADDIE a waterfall model that follows the traditional way of steps, SAM is a cyclic based model. SAM an Agile-based Iterative model that proposes a short method of training with a limited time frame. The learning objective arrived during the particular time frame, needs to be applied rapidly. 


\section{A Comprehensive Framework for Adaptive E-Learning Management System}

The information gathered by the learner is fast and effective than the ADDIE approach. SAM includes three phases of development. The initial stage begins with the preparation, in these, the background details of the learner's needs and the solution to the needs are finalized. The next stage focuses on designing a prototype based on the ideas, presumptions from the parties. The last phase is applied based on the instructional design proposed by the iterative design and leads to the development of the Alpha version of the Model. The conversion moves to the Beta version while attending to the queries made in the feedback. A final one is converted into a Gold version.

Table-VI. Successive Approximation Model (SAM)

\begin{tabular}{|c|c|}
\hline Phases & Description \\
\hline Preparation & Information collection and practical Knowledge \\
\hline Iterative Design & Prototype and Design \\
\hline Iterative & Development and Evaluation (Beta \& Alpha \\
Development & version) \\
\hline
\end{tabular}

The main advantage of this approach is the learner gets a quick response towards the course in which it helps to deliver the learning outcome within the expected time.

\section{ASSURE Model}

[16] ASSURE an instructional model focuses on the specific needs of the learner in each step. Instead of stringing technology as a whole, ASSURE concentrates on individual objectives and the technology need to achieve their goal or objective. The ASSURE model is a best-fit model compared with the AFT and SAM in enhancing the available requirements instead of adopting a new one.

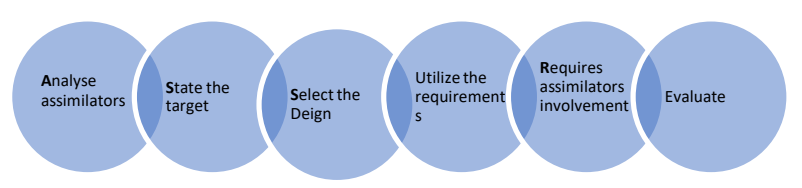

Fig.3. ASSURE instructional stages

\section{CHALLENGES IN E-LEARNING MODEL}

The real challenges in the current e-learning scenario is the instruction given to the particular learner category will not work out or suit to the rest of the learners. Choosing the learner category goes a viral number of steps. Each learner has a unique learning style and the instructional model for that particular learner to be varied in order to produce a unique learning outcome. The main challenge is to collect and prefetch the learner profiles and the technology preferred to them. Each of these need to be addressed and studied in a particular interval of time. All these could not be done in one single framework. There needs to be an integrated component that connects all these generic frameworks into a single framework. The e-learning framework in the recent eras needs to include various principles that useful in dealing with learner styles, outcomes, and content. principles reflection should meet in improving learner praxis. The commonly accepted learning styles are very rare to produce between the existing frameworks. From the above various frameworks and learning models, applied science and prediction of the learner does not meet the learning path. To understand this tutor still to have a comprehensive study over different available and current prevailing learning styles, paths, content, and outcome.

\section{PROPOSED MALE FRAMEWORK}

The proposed architecture enables the e-learning system to adapt different learning properties and provide a learner-centric approach. Over half the percentage of the current e-learning model \& technology does not meet the learner requirement \& expectations. The figures and the framework lack to prompt the tutor's concern over the learner in any of the modules that we have discussed above different learning models. Constant knowledge, style and preference of the learner are never known inside the classroom. To bridge these gaps and to provide constant learning content, instruction and outcome the MALE framework combines all the modules and breaks down into four generic concepts.

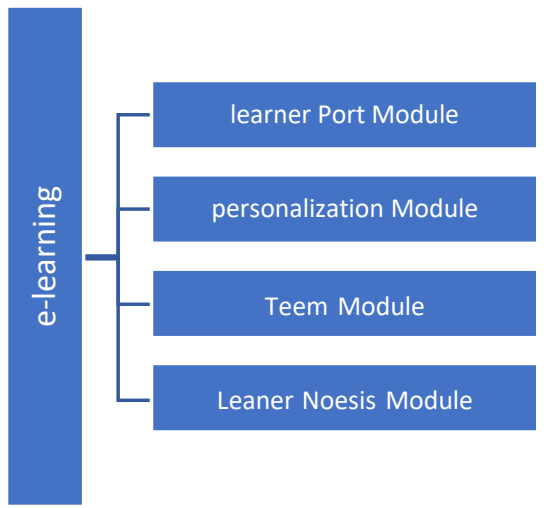

Fig.4. Overview of e-learning Framework

The first layer presents the most properties regarding the current learner preference and characterization. The second layer consists of the various personalization approach which helps to adapt and predict the learning style. It comprises of learning algorithms that help in predicting the model. The third layer focuses on current technology. These properties provide an in-depth account of the different learning dimensions of the MALE framework. It narrates the concepts related across the properties and how it is being applied by the learner, tutor and naïve learners. The design properties are a contribution to the learner to channelize different e-learning disciplines. This framework property integrates leaners, styles technology and repository collections.

Table-VII: The taxonomy framework Design for e-learning

\begin{tabular}{|c|c|}
\hline Domain & Properties \\
\hline \multirow{4}{*}{$\begin{array}{l}\text { Learner } \\
\text { Port } \\
\text { Module }\end{array}$} & Load Balancer \\
\hline & Learner Aesthetics --learner experience \\
\hline & User profiling - Individualized profile \\
\hline & Didactics Models - Learning pedagogy \\
\hline \multirow{4}{*}{$\begin{array}{c}\text { Personalization } \\
\text { Module }\end{array}$} & Learner Style \\
\hline & User Experience \\
\hline & Machine Learning Algorithm \\
\hline & Learning paths \\
\hline \multirow{4}{*}{$\begin{array}{l}\text { Tech Enabled } \\
\text { Module }\end{array}$} & Cyberspace Tools \\
\hline & Learning Resources \\
\hline & Core services (web 4.0, 5.0) \\
\hline & Miscellaneous \\
\hline \multirow{5}{*}{$\begin{array}{c}\text { Learner Noesis } \\
\text { Object } \\
\text { Module }\end{array}$} & Metadata \\
\hline & Data weighting \\
\hline & Data Feedback \\
\hline & Data Privilege \\
\hline & Learning Target \\
\hline
\end{tabular}




\section{A. Learner Port Module}

\section{- Load Balancer}

A load balancer focuses on the distributed infrastructure to defend the workload balancing problem. The input is received by the load balancer distributes and delivers fast responses to the learner [17]. The e-learning framework The request gets into each of the domains through the load balancer. It does the routing by taking the request and directing it to the particular domain. It will consider the different request from learner and takes to the appropriate domain. All these requests could be from different or same user. It efficiently distributes the request across the multiple domains. It considered to be one of the important properties of the learner port module. A load balancer helps in easily configuring by adding or reducing more servers.

The learner perception focuses on a student-centric approach. The recent locomotion from teacher/instructor-centered approach to student-centered approach is due to the proactive engagement of the student (learner). The proactive engagement of the learner is met by the requirements from the learner experience. Most of the individual experiences are taken into account from e-books, MOOCs, and online learning and based on the past experience. The learning experience empowers meaningful knowledge to the learners

\section{- Learner Aesthetics}

Aesthetics is a fork of philosophy that deals with senses that notates and helps to discover new ways of learning, speaking in everyday learning like hands-on inquiry, writing \& reading skills. This module classifies the learning styles according to the taste of the learner from the user profile. The ethical interventions are made possible by the aesthetic style of learning. Aesthetics learning deals with audio and visual representations, movements, verbal expression styles. This different expression helps in developing the integral formation of a learner's personality [18]. In this way of learning, the learner's confidence level gets increases as they poise and involve more. In the aesthetic module, the learner approaches change once they chose the learning style and the view differs from others resulting in the development of the personality. The pattern chosen by the learners will differ from another one. Learner Aesthetic can be delivered well through the symbol representation as $\mathbf{C}=$ Creation, $\mathbf{E}=$ Evaluation and $\mathbf{E x}=$ Experience.
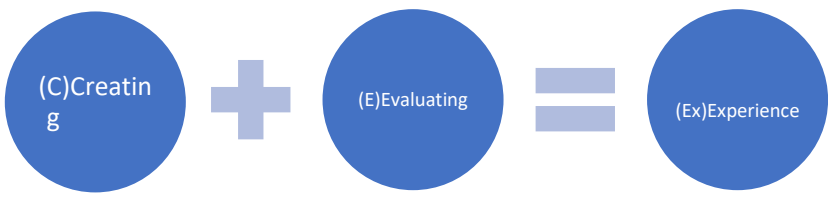

Fig. 5. Aesthetic learning task explanation in symbol - User Profile representation

The personalized or individualized profile will help to categorize the learner in gender-wise (male or female), qualification (different levels) and their domicile classification. The learner's characteristics are related to the individual profile [19]. It helps to classify the user to choose their personalization based on their profile classification. Personal Dimension is a classification derived from the learning style of the individual learner. This module can be stored in a repository from where the learner can find a new deploys many domains that relate to the single User Interface.

learning style category. The dimension module adopts the intercultural abilities and culture of new education from the learner style classification. The dimensions are grounded on the different interactions made by the learner. Attributes of the learner has a tendency to change from subject to subject.

\section{- Didactic Module}

The didactic model is based on the learning outcome of the learning style from the individual learner. It shows the pedagogical design of the learner. The learning outcome is based on the appropriate response from the reinforcement approach by the learner. In this module, the learning style gets structured and derived performance of the various learning style. In the next module, the didactic module needs to meet the requirement of the individual learner by adapting various algorithms. The didactic model that brings in the module get struck when brought into the classrooms.

\section{B. Personalization Module}

The destination and idea to frame these properties is to furnish personalized content to enrich the learning experience of the learner based on the learning properties discussed below. The didactic model gets struck when brought inside the classrooms. To make effective personalization the learning content provided to the learner demands adaptiveness according to the learner characteristics. Fundamentally the personalization technique is done at three levels. The learner predictions is articulated in general form and presented from the framework properties in order to identify the different type of learners.

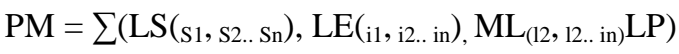

\section{Table -VIII: Personalization techniques classification}

\begin{tabular}{|l|l|}
\hline \multicolumn{1}{|c|}{ Classification } & \multicolumn{1}{c|}{ Explanation } \\
\hline $\begin{array}{l}\text { Personalized } \\
\text { Representation }\end{array}$ & $\begin{array}{l}\text { Presentment of the learning materials fitting } \\
\text { to learner style }\end{array}$ \\
\hline Personalized Content & $\begin{array}{l}\text { Deliverance of the learning resources in } \\
\text { preference to the learner style }\end{array}$ \\
\hline $\begin{array}{l}\text { Personalized } \\
\text { Navigation }\end{array}$ & $\begin{array}{l}\text { Adaptation of navigation through learning } \\
\text { path }\end{array}$ \\
\hline
\end{tabular}

The learning properties classification is useful in the contribution of learner performance, and to predict their pattern of learning style. This technique finds practicable by applying personalization (1) that makes an impact on the learning environment. Each component in the personalization module act as a reacting factor to promote a personalized learning path.

Table - IX: Representation and description of the personalization module

\begin{tabular}{|c|l|}
\hline Representation & \multicolumn{1}{c|}{ Description } \\
\hline PM & Personalization Module \\
\hline LS & Learning Style \\
\hline S1, S2.. Sn & Different types of Learner style classification. \\
\hline LE & Learner Experiences \\
\hline ML & Machine Learning algorithm \\
\hline l1, l2 & l stands for different classifications of algorithm \\
\hline LP & Learning Path \\
\hline
\end{tabular}

Information reaches and gains a lot when it has a specific style or doing it in own style. The own style ranges as discussion or in explanation. 


\section{A Comprehensive Framework for Adaptive E-Learning Management System}

The style changes decade to decade. From tradition to advanced lots of styles have been introduced in order to promote the learning ability of the learners. Some of the learning styles much practiced are classified below from various models.

Table- X: Learner style classification based on adaptive e-learning

\begin{tabular}{|l|l|l|}
\hline $\begin{array}{c}\text { Learning Style } \\
\text { Attribute }\end{array}$ & \multicolumn{1}{|c|}{ Type } & \multicolumn{1}{|c|}{ Description } \\
\hline LSA1 & Visual & $\begin{array}{l}\text { Able to remember by picture, } \\
\text { images. }\end{array}$ \\
\hline LSA2 & Verbal & $\begin{array}{l}\text { Remember through repeated } \\
\text { hearing. }\end{array}$ \\
\hline LSA3 & $\begin{array}{l}\text { Sense } \\
\text { (kinesthetic) }\end{array}$ & $\begin{array}{l}\text { Learning through feel, touch or } \\
\text { imagination. }\end{array}$ \\
\hline LSA4 & Tralatitious & $\begin{array}{l}\text { Learning by avoiding modern } \\
\text { educational tools. Basic learning } \\
\text { styles. }\end{array}$ \\
\hline LSA5 & Standalone & $\begin{array}{l}\text { Learner prefers to learn without } \\
\text { any style. }\end{array}$ \\
\hline LSA6 & Piteous group & $\begin{array}{l}\text { Learner style for piteous category } \\
\text { student }\end{array}$ \\
\hline LSA7 & Sequential & $\begin{array}{l}\text { Learners following step by step } \\
\text { action. }\end{array}$ \\
\hline LSA8 & Global & Learners with big initiatives \\
\hline
\end{tabular}

The learner level mentioned above is exempted from the advanced and traditional since they do not possess any demonstrative method of learning. The other learner style may need to adapt the learning style that could be derived from the Learner port module.

$\mathrm{LS}=\{\mathrm{LSA} 1, \mathrm{LSA} 2, \mathrm{LSA} 3 \ldots \mathrm{LSAN}\}$

The learner style arrives from the didactic model from the learner port. Learner style focus on the different learning category. MALE Framework helps in defining the learning style of the Preferred learner. In basic the learner style content delivery basically built-in verbal and visual content format. The learner style differs from person to person approach. Some are good at learning visually; another type can respond to aural and the rest may interest in learning by sense which enhances to experimental model.

From the Learner Style (2), the Learning path provides the learners to be the masters of the subject they prefer or wish to work upon. The learning path helps in improving the performance standard. It purely based on the list of learners previously mastered and experienced with resembling characteristics. It helps in choosing the action, based on the most adapt outcome [20]. The personalized learning path paves way for generating a specific learning path where the cost of response time and effective path is generated. The generalized quadruple format of learning path as given in the format (3)

$\mathrm{LS} \rightarrow \mathrm{LE} \rightarrow \mathrm{ML} \rightarrow \mathrm{LP}$

Where,

LS - Learner's Style

LE - Learning Experience

ML - Machine Learning

LP - Learner Path

\section{TEEM Module}

The burgeoning of e-learning found to be effective with the technology adopted. TEEM (Tech-Enabled Module) is a connecting platform for all three modules. Learning and technology are the key areas in the construction of the e-learning model. In the initial level of learning, technology is the key factor for delivering the learning cognitive to the hands of learners. The technology underpins the situations, bridges various dimensions and helps in the aggregation on various tools [21]. The visualization of the learner in choosing the styles still to the transformation of the repository is organized and streamed by the Teem Module. It hopes for the steady growth in learner categories. The technology module helps in the collaboration of the tutor and the learner. The learning gets toughened with technology chassis the tutor knowledge by bridging the gap conducting the regular assessment and evaluation with the help of the TEEM Module. This TEEM Module will help to engage the teaching-learning process in a seamless promoting the various and recent technology adapted techniques.

The technology listed in the TEEM will advance the learning ability for better learning and delivering the learning style and learning path (2) \& (3). The difference in teaching and learning paradigm in recent trends and the main impact for the change is done thought the adaptive technology. 


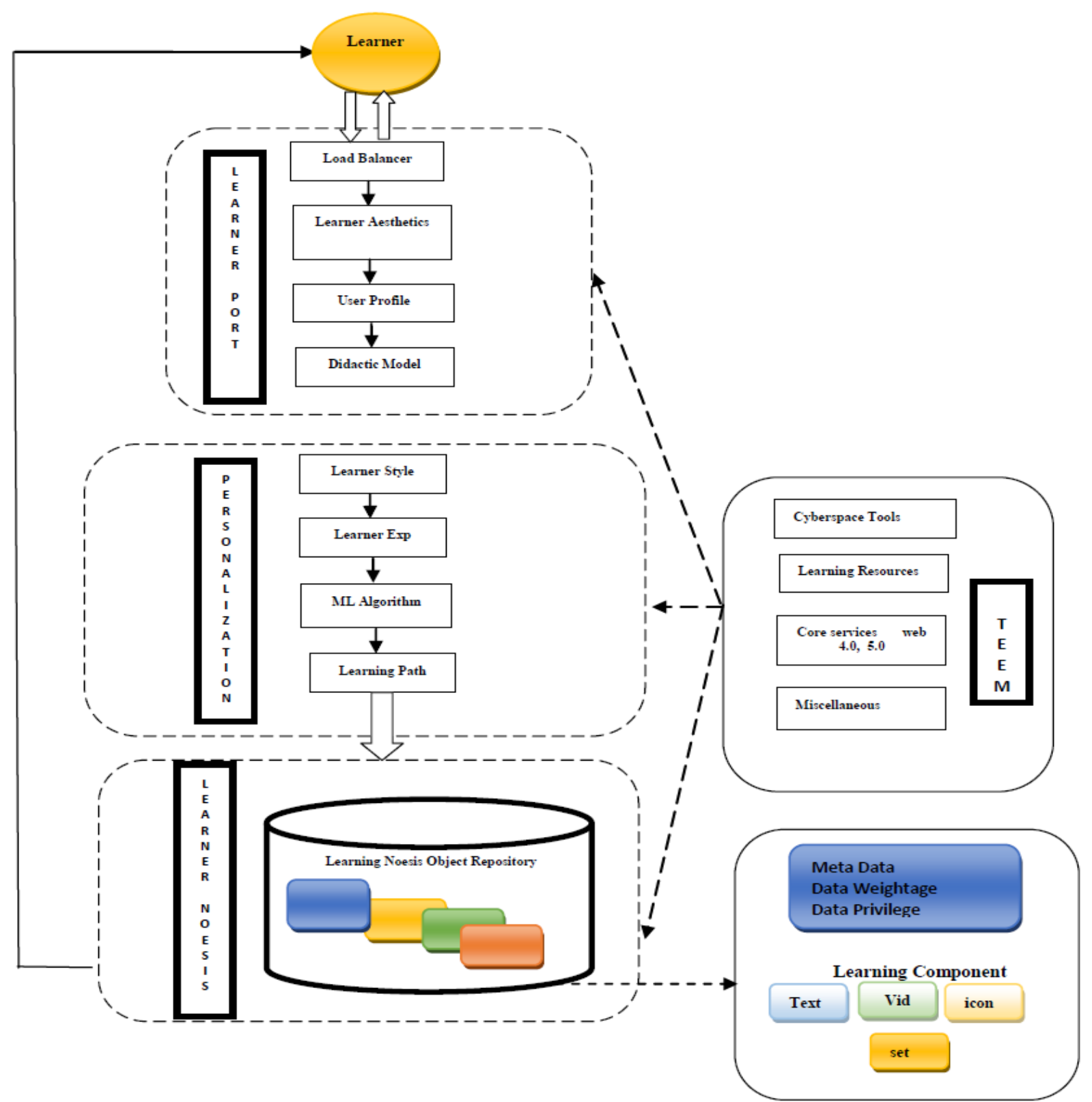

Fig. 6. Proposed MALE Adaptive Framework Taxonomy

Table- XI: Various Tool analysis In TEEM Module

\begin{tabular}{|c|c|}
\hline $\begin{array}{c}\text { Technology } \\
\text { Tools }\end{array}$ & Concept \\
\hline $\begin{array}{c}\text { Cyberspace } \\
\text { Tools }\end{array}$ & $\begin{array}{c}\text { Focuses on FTP services, www, discussion in group via } \\
\text { mailings reading contents via e-paper, magazines. }\end{array}$ \\
\hline Web 4.0 & Intelligent learning, self-learning, virtual learning. \\
\hline Web 5.0 & $\begin{array}{c}\text { Bring in the emotion between tutor and learner to make } \\
\text { more interaction. }\end{array}$ \\
\hline Learning & $\begin{array}{c}\text { It balances teaching with learning resources such as } \\
\text { gamification, } \\
\text { Resources }\end{array}$ \\
\hline Miscellaneous & Other services tools that helps to bridge the technology \\
\hline
\end{tabular}

\section{Learner Noesis Object Module}

The primary prospect of the learner repository module is promoting personalized learning. The learner noesis is a repository collection of all the learning style categories. It classifies the module structure within the noesis module from the MALE taxonomy. The learning repository phases into four structures according to the learner style scenario. The word learner-centric find exact meaning where the data is centralized for easy and efficient retrieval. The learner's noesis module act to be a centralized repository classifying the learner learning objects of the targeted group of learners. To retrieve the information faster data metadata type of illation is required. The personalized learning object is stored as repositories in the learner's noesis module. The distributive repository system is needed when the volume of styles and learning paths increases and it paves way for easy illation and response time is quick. The learning outcome is hive away as below module representation.

Table- XII: Content drawn on Noesis Module in MALE framework.

\begin{tabular}{|l|l|l|}
\hline MALE & \multicolumn{1}{|c|}{$\begin{array}{c}\text { Learning } \\
\text { Components }\end{array}$} & \multicolumn{1}{|c|}{ Structure details } \\
\hline Unit & Textual & $\begin{array}{l}\text { Materials that related to textual content, } \\
\text { helps in the development of learning. }\end{array}$ \\
\hline Unit & Vid & Materials in video representation \\
\hline Unit & Icon & $\begin{array}{l}\text { All the picture related contents are } \\
\text { supported by the icon components }\end{array}$ \\
\hline Unit & set & $\begin{array}{l}\text { It bound the value of the location or the } \\
\text { ratio }\end{array}$ \\
\hline
\end{tabular}

Published By:

\section{\& Sciences Publication}


From phase one learner port content is stored in the repository were in turn produced as an outcome for choosing the learning taste. It can be used as one of the data set to classify the learner's taste. The learning experiences are based on the learner preference, taste. The classification is based on the learner aesthetics. The learner's taste is grouped and services are grounded on the recommendation. The user profile-based learner content is stored in this module. The Learner content repository. The instructive model outcome is categorized in the repository which derives from the learning style. Later the instructive model becomes the structure for future recommendation systems. The Management module delivers the method to build repositories of personalized learning in need of reusability of learning objects for a prognostic model. The learner management repository is a digital depot, process and easy to retrieve the learner content and object. The learner Feedback and evaluation repositories progresses based on the feedback, improvement measures added to the learning object and content. The learning objects drawn based on the contents could be engineered as knowledge capsules consist of the learning stuff. The delivery model of this stuff consists of aesthetic learning types (different tastes of learners).

\section{E. Learning Object Repository}

The learning Noesis objects are comprised of Learning Object intended in the development of active learning. For an individual learning object placed in the noesis repository. The repository module is ordered, placed according to the frequent and quick response to the learner.

The learning Object stored in the Metadata helps in better infer through other techniques. The execution of the reusability of the resources is made possible by the data management and usage technique [20]. The important keywords are highlighted for easy reference of the data. The metadata highlighted in the LO component is discussed below. The data weightage specifies about the $\mathrm{LO}$ as listed by the author according to the inference. Data privilege is another LO type category. The learning components associated are to satisfy the needs of the respective learners. It provides the basic needs of the learners. The components can be textual, vid, Icon and set. These components will help in delivering the course content which is supported by learning object development tools. The learning path (3) helps to identify the level of the learner and to choose the learning style. If the model is identical, it becomes the new model to the system repository. The learning Materials also described as Learning Objects (LO). LO helps to present the learning material in popular format such as PPT (PowerPoint for presentation), Adobe Flash (design). The Learning Object Management Tools helps in the promotion of Learning Management Systems. LMS act as an integrated part, of course, student management, feedback management, online material, and assessment. Both the Learning Object development tool and Learning Management Tool help in supporting learning components. The LO derived in the repository are converted and customized according to the learning path generated and send it to the learner as a model.

\section{CONCLUSION AND FUTURE WORK}

From the panoptical view of the existing frameworks and related works an adaptive learning management system based on learning styles, this framework will help the students and teachers to find better learning path. The main aim of developing the MALE framework is to fit in any algorithm which will lead to a better learning path including Machine Learning. This way of system keeps gathering further information through feedback analysis and promotes personalization for a better and richer framework. Learning fall out anytime, anywhere and it is made available and possible through e-learning. The utmost service provided by e-learning will be making the content, materials available which make the educative disciplines more pliable and approachable. In time the MALE framework can be fit in with any adaptive model that enhances the teaching-learning process. The proposed system will help to find out the better learning path in specific to the beginners who struggle to find better learning style. This will be fulfilled by the Machine Learning (hybrid analysis) to generate the learning path from MALE framework.

\section{REFERENCES}

1. Robert Gogos "A brief history of e-Learning (infographic)", 2012.

2. Steeve Wheeler, "e-Learning and Digital Learning" University of Plymouth, UK, DOI: 10.1007/978-1-4419-1428-6_43

3. Gabriella Carmen, “A study about Using E-learning Platform (Moodle) in University Teaching Process" Article in Procedia - Social and Behavioral Science, 2015.

4. Jamilah A. Alokuk, "The effectiveness of Blackboard System, Uses and Limitations in Information Management", Intelligent Information Management, Jan 2018, Jan 2018.ISSN 2160-5920.

5. Fátima Faya Cerqueiro,, "Socrative in Higher Education", Faculty of Education of Toledo, University of Castilla-La Mancha, 6 July 2019.

6. statmati crook, "Embedding Scratch in the classroom"

7. Lory Hough, "Tool in Shcool: Quizlet", Harward Graduate School of Education.

8. Mostafa Al-Emran \& Rana A. Saeed, "Students Acceptance of Google Classroom: An Exploratory Study using PLS-SEM Approach" Al Buraimi University College, Al Buraimi, Oman.

9. “Adobe Spark-A guide for School and Educators"-2018.

10. Michael J Petrides \& Gary G, "Seesaw: The Learning Journal-Verasatile Digital Portfolio" School Staten Islan, United States.

11. Maryanne Chiarelli, Suzan Williams \& Susan Szabo, "Using ClassDojo To Help with classroom Management during guided reading”, Texas Journal of Literacy Education, Volume 3, Issue 2, 2015.

12. Zajacova, "Learning Styles: An Overview of Concepts and Research Tools and Introduction of Our Research Design in Physics Education Field “, ISBN 978-80-7378-252-8, Pages 91-96, 2013.

13. Linda K. Silverman \& Richard M. Felder, "Learning and Teaching Styles in Engineering Education.”, Engr. Education, 78(7), 674-681. 1988.

14. Edan Kentris, "The AFT Model for eLearning", Training Industry blog, 2018.

15. Younglong Kim \& Hyojung Jung, “Advanced Instructional Design for Successive E-Learning: Based on the Successive Approximation Model", International Journal of E-learning, PP 191-204, March 2019

16. Kurt S, "ASSURE: Instructional Design Model", Educational Technology, 2015.

17. Olga Denac, "The Significance and Role of Aesthetic Education in Schooling", Vol.05 No.19, 2014.

18. Maria Dominic \& Sagayaraj Francis, "An Adaptable e-Learning Architecture Based on Learner Profiling”, Vol 3, PP. 26-31, DOI: 10.5815/ijmecs.2015.03.04, 2015.

19. Mark McDaniel \& Harold Pashler, "Learning Styles Concepts and Evidence" Mark McDaniel \& Harold Pashler, Volume: 9 issue: 3 page(s): 105-119 2009, DOI.1539-6053.

20. Maria Fasli \& Christos Chrysoulas, "Building an Adaptive E-Learning System".

21. Nikos Mastoraks \& Hazem M El-Bakry, “Adaptive e-learning based on Learner's styles", Bulletin of Electrical Engineering and Informatics, ISSN: 2089-3191. 


\section{AUTHORS PROFILE}

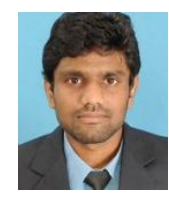

Mr. Shinoj Robert is a part time research scholar in the Department of computer Science, Sacred Heart College, Tirupattur Dt, and working as an Assistant professor from 2014 in the Department of Computer Application, Don Bosco College, Yelagiri Hills, and His area of research in the field of Machine learning and E-learning.

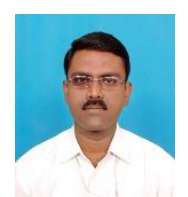

Dr. M. Maria Dominic obtained his B. Sc, M.Sc., M.Phil. and $\mathrm{PhD}$ in Computer Science. He has been working in Sacred Heart College, from 1996 onwards at various capacities He has also worked in Multimedia University, Malaysia on a Contractual Basis. He has co-authored a book on OOP using $\mathrm{C}++$ published by Pearson education. He has published more than 20 research articles in International Journals. He has $4 \mathrm{PhD}$ Research scholars working under him in the field of Artificial Intelligence especially in Machine learning and Deep Learning. 